\title{
Risk assessment and prediction of complications in pregnant women with heart disease
}

\author{
Anahita R. Chauhan*, Neha Saxena
}

Department of Obstetrics and Gynecology, Seth GS Medical College and KEM Hospital, Mumbai, Maharashtra, India

Received: 04 September 2017

Accepted: 09 September 2017

\section{*Correspondence:}

Dr. Anahita R. Chauhan,

E-mail: anahitachauhan@gmail.com

Copyright: (C) the author(s), publisher and licensee Medip Academy. This is an open-access article distributed under the terms of the Creative Commons Attribution Non-Commercial License, which permits unrestricted non-commercial use, distribution, and reproduction in any medium, provided the original work is properly cited.

\begin{abstract}
Background: There is a vast improvement in the survival and quality of life of patients with both major and minor structural and functional cardiac defects. Objective of present study was to calculate CARPREG (CARdiac disease in PREGnancy) risk score and test its efficacy in predicting the occurrence of adverse maternal cardiac events in patients with heart disease.

Methods: This was a prospective observational study where CARPREG score was calculated for 100 pregnant patients as soon as they were enrolled and the degree of risk and maternal complications were recorded and studied in relation to the score.

Results: Out of the 100 patients included in our study, it was found that Rheumatic heart disease (69\%) with isolated mitral stenosis was the predominant cardiac problem. Maternal cardiac events complicated $14 \%$ pregnancies with congestive cardiac failure occurring most frequently. The complication rate was $1.56 \%, 5.56 \%$ and $66.67 \%$ in patients with CARPREG score of 0,1 and $\geq 2$ respectively. The sensitivity, specificity, positive predictive value and negative predictive value of CARPREG score in predicting the complications were $66.67 \%, 97.56 \%, 85.71 \%$ and $93.02 \%$ respectively. Hence, the score was efficacious in predicting the maternal cardiac complications and was found to be a statistically significant predictor of maternal complications ( $p$ value $=7.39 \mathrm{E}^{-06}$ ).

Conclusions: The CARPREG risk index has a high specificity and negative predictive value with regards to cardiac complications in pregnant women with heart disease. It may, therefore, be routinely used to improve the assessment of cardiac risk before and during pregnancy.
\end{abstract}

Keywords: CARPREG score, Cardiac complications, Rheumatic heart disease

\section{INTRODUCTION}

There is a vast improvement in the survival and quality of life of patients with both major and minor structural and functional cardiac defects. This is mainly attributed to the improved imaging and diagnostic modalities in modern medicine and advancing surgical care. 1 As a result, women with even complex heart diseases survive more frequently to childbearing years and pregnancy has become feasible for them. Hence a very sophisticated and multidisciplinary approach is necessary for the care of pregnant women with heart disease.

Congenital heart diseases (CHD) are the most common birth defects in humans, affecting approximately $0.8 \%$ of all live births. Studies have shown that up to $4 \%$ of pregnancies may have cardiovascular complications despite no known prior heart disease. Physiological adaption to pregnancy causes significant changes in cardiovascular system to meet the increased metabolic requirement to the growing fetus. However, women with 
pre-existing cardiac lesion may decompensate with resultant increased maternal and perinatal morbidity and mortality.

The risk of pregnancy and the complications depend on the specific heart disease and clinical status of the patient. A risk assessment should be performed prior to pregnancy and repeated antenatally, and hospital delivery should be advised. ${ }^{1,2}$

The various risk factor assessment models available include the modified WHO score and the CARPREG score. While both perform well, different studies have shown different results.

Ours is a tertiary care centre with well renowned cardiology and cardiothoracic surgery departments and a large number of pregnant women with cardiac disease. However, to date since very few studies have used systematic scoring to calculate the risk of adverse maternal cardiac events; a prospective study of cardiac disease in pregnancy to ascertain the value of CARPREG Score was conducted.

The need for such a study arises because evidence is inconclusive and some authors content that no risk model is completely useful. ${ }^{3}$

Objectives of present study were to calculate the CARPREG score and assess the degree of maternal risk/ complication in relation to the score and to test the efficacy of CARPREG score in predicting the occurrence of adverse maternal cardiac events.

\section{METHODS}

A prospective observational study carried out in a tertiary hospital over a period of 1 year, where 100 pregnant women with heart disease fulfilling inclusion criteria were studied. The study began after due institutional ethics committee approval. All pregnant women more than 18 years with any diagnosed cardiac disease (congenital, rheumatic, cardiomyopathies, ischaemic or others) and haemoglobin level more than $8 \mathrm{gm} / \mathrm{dl}$ were included. Pregnant women with pre-existing co-morbid conditions and with major congenital abnormality in the foetus on antenatal scan were excluded from the study.

The CARPREG score was applied to all patients as soon as they were enrolled and the degree of risk was assessed in relation to the score. The risk score included one point each for the following parameters and the total score was calculated by addition of each of these points.

Siu et al found that the chances of maternal cardiac complications were 5\%,27\% and $75 \%$ with CARPREG risk score of 0,1 and $\geq 2$ respectively.

The patients were enrolled at various gestational ages, as when they presented to the antenatal care OPD, or emergency services department. All types of cardiac diseases were included. At the time of inclusion, patient was explained about the study and enrolled after taking due consent.

\section{Table 1: Cardiac disease in pregnancy (CARPREG) risk score (from Siu et al, 2001).}

\begin{tabular}{l} 
One point for each \\
History of prior cardiac event or arrhythmias \\
$\begin{array}{l}\text { New York Heart Association functional class }>\text { II or } \\
\text { cyanosis }\end{array}$ \\
$\begin{array}{l}\text { Left heart obstruction (mitral valve area }<2 \mathrm{~cm}^{2}, \\
\text { aortic valve area }<1.5 \mathrm{~cm}^{2}, \text { or left ventricular outflow } \\
\text { tract gradient }>30 \mathrm{mmHg} \text { ) }\end{array}$ \\
Left ventricular ejection fraction $<0.40$ \\
\hline
\end{tabular}

The patients were followed up through their pregnancy. All details regarding antenatal care follow up were noted. The nature of cardiac lesion and severity of medical disorder was noted. Also noted was the problems encountered during pregnancy such as presenting in emergency breathlessness or congestive cardiac failure or arrhythmia or any other problems. The antepartum, intrapartum and postpartum events were noted. Need for ICU admission and other interventional procedures were also noted. The initial risk estimated by CARPREG score was compared with the actual occurrence of the maternal adverse events.

Simple comparative statistics (t-test) was used for comparison within groups. Positive predictive value and negative predictive values were estimated using standard statistical definitions. Binary logistic regression test was performed to assess the accuracy of CARPREG score in predicting maternal adverse event.

\section{RESULTS}

In present study, majority (43\%) of the patients were in the age group of 24-28 years and two-thirds were either primigravida or primipara. $79 \%$ of the patients presented with dyspnoea on exertion as their predominant symptom. $67 \%$ patients were diagnosed to have heart disease prior to pregnancy, however in the rest, diagnosis was made primarily during their present pregnancy. Out of the $6 \%$ patients who had prior cardiac events, cardio embolic stroke was the commonest. Rheumatic heart disease $(69 \%)$ with isolated mitral stenosis was the predominant cardiac problem. However, septal defects were the most common form of congenital heart disease, out of which atrial septal defect was the commonest, seen in approximately half of the cases of CHD. 3\% had cardiomyopathy, including both dilated and peripartum cardiomyopathy. Less commonly we had cases with ectopic beats, pericardial effusion and ischaemic heart disease. Mitral valve area of less than 2 was seen in $29 \%$ patients on $2 \mathrm{D} \mathrm{ECHO}$ while in the rest it was more than 2. Also, only $2 \%$ cases had LVEF less than $40 \%$ while the rest $98 \%$ had LVEF of more than $40 \%$. Cardiac 
complications were seen in $14 \%$ patients out of which majority patients developed congestive cardiac failure and arrhythmia was noted in a few. However, $86 \%$ patients who had uneventful antepartum, intra partum and post-partum course.

Table 2: Application of CARPREG score to the study population.

\begin{tabular}{|lll|}
\hline CARPREG score & No. of patients & $\%$ \\
\hline 0 (low risk) & 64 & 64.0 \\
\hline 1 (intermediate risk) & 18 & 18.0 \\
\hline$\geq 2$ (high risk) & 18 & 18.0 \\
\hline Total & 100 & 100.0 \\
\hline
\end{tabular}

12 patients $(85.7 \%)$ had a CARPREG score of 2 or more, $\mathrm{p}$ value was $7.50 \mathrm{E}-06$, signifying that there is a strong association between the maternal complications and the severity of CARPREG score. There were two maternal mortalities; both succumbed due to congestive cardiac failure. Spontaneous vaginal delivery is seen as the commonest mode of delivery in heart disease cases. Out of 95 deliveries there were 40 full term normal vaginal deliveries, 26 lower segment caesarean sections, 19 delivered as preterm and forceps application was done in 10. There were 5 patients who did not continue the pregnancy and had undergone medical termination of pregnancy.

In present study, we found that $64 \%$ patients had a CARPREG score of 0 , whereas $18 \%$ patients had a CARPREG score of 1 and the rest $18 \%$ had a score of 2 or more.

The $\mathrm{p}$ value for maternal age was calculated as 0.02 ; which was a statistically significant association between maternal age and CARPREG score in current study.

Table 3: CARPREG risk score and chance of maternal cardiac complications.

\begin{tabular}{|ll|}
\hline $\begin{array}{l}\text { CARPREG risk } \\
\text { score }\end{array}$ & $\begin{array}{l}\text { Chance of maternal cardiac } \\
\text { complications }\end{array}$ \\
\hline 0 & $1.56 \%$ \\
\hline 1 & $5.56 \%$ \\
\hline 22 & $66.67 \%$ \\
\hline
\end{tabular}

The complication rate was $1.56 \%, 5.56 \%$ and $66.67 \%$ in patients having CARPREG score of 0,1 and $\geq 2$ respectively, which correlates well with the score ( $p$ value 0.047 - statistically significant).

Sensitivity of the test was $66.67 \%$; specificity was $97.56 \%$, positive predictive value of $85.71 \%$ and negative predictive value of $93.02 \%$ for maternal cardiac events. Hence the CARPREG score was found to be effective in predicting the maternal cardiac complications with a sensitivity of $66.67 \%$ (CI of $40.99 \%$ to $86.66 \%$ ) and specificity of $97.56 \%$ (CI of $91.47 \%$ to $99.70 \%$ ). The $p$ value in our study was $1.41 \mathrm{E}^{-09}$. Hence, we proved that the score was significant in predicting maternal cardiac complications. Binary Logistic Regression was performed between maternal complication as dependent variable and CARPREG score as independent (predictor) variable with the significance of $7.39 \mathrm{E}^{-06}$, hence concluding that CARPREG score is statistically significant predictor of maternal complication; and higher the CARPREG score, more chance of maternal complications.

Table 4: CARPREG risk score and maternal cardiac complications.

\begin{tabular}{|lllll|}
\hline $\begin{array}{l}\text { Maternal outcome } \\
\text { complications }\end{array}$ & \multicolumn{3}{l|}{$\begin{array}{l}\text { CARPREG } \\
\text { score }\end{array}$} & Total \\
\hline Yes & No. & 12 & $\mathbf{0 + 1}$ & \\
\hline & $\%$ & $85.7 \%$ & $14.3 \%$ & $100.0 \%$ \\
\hline No & No. & 6 & 80 & 86 \\
\hline & $\%$ & $6.97 \%$ & $93.03 \%$ & $100.0 \%$ \\
\hline Total & No. & 18 & 82 & 100 \\
\hline & $\%$ & $18.0 \%$ & $82.0 \%$ & $100.0 \%$ \\
\hline
\end{tabular}

*p value $1.41 \mathrm{E}^{-09}$ (statistically significant)

Table 5: Efficacy of CARPREG score.

\begin{tabular}{|llll|}
\hline $\begin{array}{l}\text { Tests of } \\
\text { efficacy }\end{array}$ & Value & $\begin{array}{l}\text { Lower 95\% } \\
\text { confidence } \\
\text { interval (CI) }\end{array}$ & $\begin{array}{l}\text { Upper 95\% } \\
\text { confidence } \\
\text { interval (CI) }\end{array}$ \\
\hline $\begin{array}{l}\text { Sensitivity } \\
\text { Specificity }\end{array}$ & $66.67 \%$ & $40.99 \%$ & $86.66 \%$ \\
\hline $\begin{array}{l}\text { Predictive } \\
\text { value of } \\
\text { positive test }\end{array}$ & $85.71 \%$ & $57.19 \%$ & $98.22 \%$ \\
$\begin{array}{l}\text { Predictive } \\
\text { value of } \\
\text { negative test }\end{array}$ & $93.02 \%$ & $85.43 \%$ & $97.40 \%$ \\
\hline
\end{tabular}

\section{DISCUSSION}

Heart disease complicating pregnancy is considered as a high-risk situation. The magnitude of the risks of cardiac complications during pregnancy varies depending on the type and severity of the underlying disease. However, in a developing country like ours, many cases tend to get missed owing to lack of awareness; also, the majority population lives in rural areas where health care facilities are either inappropriate or inadequate. This poses an additional risk for such high-risk patients in whom either the diagnosis is not made accurately or diagnosis is made at such a level where the clinical condition of the patient has already deteriorated owing to the type and severity of the underlying cardiac lesion. The maternal and perinatal outcome in such high-risk patients can be enhanced by adequate risk assessment and counselling. In this study, we have analyzed the main risk factors of cardiac events in pregnant women with heart disease so as to justify the use of an established risk assessment system, i.e. Cardiac Disease in Pregnancy (CARPREG) Risk Score, developed by Siu et al, in $2001 .{ }^{4}$ Other investigators have 
also studied the CARPREG score and positively reported about this score. ${ }^{5,6}$ Another integrated system was proposed by an English group of experts. They adapted the World Health Organization (WHO) Medical Eligibility Criteria (MEC) guidelines for contraceptive methods, and applied the same categories to classify the maternal risk of pregnancy with cardiovascular conditions, using prospective evaluation of several risk estimation models. ${ }^{7}$ This classification has also been advocated in the new European Society of Cardiology (ESC) guidelines for the management of cardiovascular diseases during pregnancy as the risk estimation system of choice. ${ }^{8}$

According to WHO classification, pregnancies are classified into four categories, WHO Classes I, II, III and IV, which represent low, medium and high risk of pregnancy, and contraindication for pregnancy, respectively. Management advice is assigned to these risk classes as follows: cardiology follow-up can be limited to once per trimester or even less for women with low or moderate risk (WHO class I or II), women in WHO class III and IV benefit from frequent control (monthly or bimonthly) in a specialized centre.

Though we found that CARPREG score is useful in prediction of maternal adverse events, other studies have reported the modified WHO score to be better. ${ }^{9-11}$

\section{Emergence of new risk scores and markers}

To estimate the risk of pregnancy in patients with heart disease, these predictors and risk scores are just one of the tools that must be used.

Apart from clinical factors, ultrasonographic parameters like impaired uterine artery pulsatility index has also been reported to be useful to be predictive. ${ }^{12}$ Additionally, disease-specific information should always be taken into account. Several new predictors have come forward in recent studies. The use of cardiac medication prepregnancy predicted cardiovascular complications in two studies and is most likely a surrogate marker for severity of heart disease. Also, in CHD, underlying corrected or uncorrected cyanotic heart disease was associated with maternal outcome which probably reflects greater complexity of the underlying lesion. This is in line with a large systematic review by Drenthen et al concerning pregnancy and CHD Atrioventricular valvular regurgitation (mitral or tricuspid regurgitation) emerged as an independent predictor of maternal cardiac complications in a large retrospective study, despite the beneficial effect of decreasing vascular resistance during pregnancy. ${ }^{13}$ The large population may have allowed weaker predictors of complications to be identified. Additionally, some of the patients had complex underlying heart disease and compromised ventricular function which possibly added to the complication. Accurate assessment of the individual maternal and foetal risk in pregnant women with heart disease is of fundamental importance for optimal patient care. A high level of suspicion for heart disease and careful attention should specifically be given to those cases where disease is detected for the first time during pregnancy. Women at intermediate or high cardiac risk (risk score $\geq 1$ ) should receive comprehensive antepartum, intra partum and postpartum care, in order to reduce the maternal and perinatal morbidity and mortality to some extent.

Hence, we conclude that a full investigation and expert risk assessment based on any of the three available risk assessment scores be conducted, since they appear to be equivalent for practical purposes. ${ }^{14}$ As recently shown by Cauldwell et al, immaterial of what risk model is used, counselling prior to pregnancy helps the woman go through a relatively safe pregnancy. ${ }^{15}$ Such risk stratification and counselling has been emphasized by $\mathrm{Lu}$ et al. ${ }^{16}$ Maternal mortality is, however, just the tip of the iceberg: maternal complications are far more important numerically.

\section{CONCLUSION}

This was a prospective observational study which included 100 pregnant women with cardiac disease, wherein the CARPREG risk score was applied. We were able to show that

- The score was efficacious in predicting the maternal cardiac complications. The sensitivity, specificity, positive predictive value and negative predictive value of CARPREG score in predicting the complications were $66.67 \%, 97.56 \%, 85.71 \%$ and $93.02 \%$ respectively.

- The score was found to be more specific than sensitive in predicting maternal cardiac complications. Thus, a lower score implies less chance of maternal complications.

- The negative predictive value was found to be more than the positive predictive value for maternal cardiac complications, indicating that fewer complications would occur and pregnancy is relatively safe in women having a lower CARPREG score as compared to those where the score is more.

- CARPREG score is a statistically significant predictor of maternal complications; higher the CARPREG score, more the chance of maternal complication. Our study has shown that the complication rate was $1.56 \%, 5.56 \%$ and $66.67 \%$ in patients having CARPREG score of 0,1 and $\geq 2$ respectively.

- The maternal cardiac events complicated14\% pregnancies in our study with congestive cardiac failure occurring most frequently. Both the maternal deaths were attributed to congestive cardiac failure.

- Rheumatic heart disease $(69 \%)$ with isolated mitral stenosis was the predominant cardiac problem. Septal defects were the most common form of congenital heart disease, out of which atrial septal 
defect was the commonest, seen in approximately half of the cases of CHD.

- The CARPREG risk index has a high specificity and negative predictive value with regards to cardiac complications in pregnant women with heart disease. It may, therefore, be routinely used to improve the assessment of cardiac risk before and during pregnancy.

Funding: No funding sources

Conflict of interest: None declared

Ethical approval: The study was approved by the Institutional Ethics Committee

\section{REFERENCES}

1. Elkayam U, Gleicher N. Cardiac problems in pregnancy. Maternal aspects: the approach to the pregnant patient with heart disease. JAMA 1984;251:2838-9.

2. Weiss BM, von Segesser LK, Alon E, Seifert B, Turina MI. Outcome of cardiovascular surgery and pregnancy: a systematic review of the period 19841996. Am J Obstet Gynecol. 1998;179:1643-53.

3. Furenäs E, Eriksson P, Wennerholm UB, Dellborg M. Effect of maternal age and cardiac disease severity on outcome of pregnancy in women with congenital heart disease. Int Cardiol. 2017;243:197203.

4. Siu SC, Sermer M, Colman JM, Alvarez AN, Mercier LA, Morton BC et al. Prospective multicentre study of pregnancy outcomes in women with heart disease. Circulation. 2001;104:515-521.

5. Chumpathong S, Sirithaweesit C, Pechpaisit N, Suraseranivongse S, von Bormann B, Titapant V et al. Predictors for complications in pregnant women with heart disease, a retrospective study. J Med Assoc Thai. 2014;97(7):730-5.

6. Jastrow N, Meyer P, Khairy P, Mercier LA, Dore A, Marcotte F. Prediction of complications in pregnant women with cardiac diseases referred to a tertiary center. Int J Cardiol. 2011;151(2):209-13.

7. Thorne S, MacGregor A, Nelson-Piercy C. Risks of contraception and pregnancyin heart disease. Heart. 2006;92:1520-5.

8. Regitz- Zagrosek V, Blomstrom Lundqvist C, Borghi C, Cifkova R, Ferreira R, Foidart JM, et al. ESC guidelines on the management of cardiovascular diseases during pregnancy of the European Society of Cardiology. Eur Heart J. 2011;32(24):3147-97.

9. Fu Q, Lin J. Predictive accuracy of three clinical risk assessment systems for cardiac complications among Chinese pregnant women with congenital heart disease. Int J Gynecol Obstet. 2016;134(2):140-4.

10. Pijuan-Domènech A, Galian L, Goya M, Casellas M, Merced C, Ferreira-Gonzalez I. Cardiac complications during pregnancy are better predicted with the modified WHO risk score. Int J Cardiol. 2015;195:149-54.

11. Balci A, Sollie-Szarynska KM, van der Bijl AG, Ruys TP, Mulder BJ, Roos-Hesselink JW. Prospective validation and assessment of cardiovascular and offspring risk models for pregnant women with congenital heart disease. Heart. 2014;100(17):1373-81.

12. Goya M, Casellas M, Merced C, Pijuan-Domenech A, Galián L, Dos L. Predictors of obstetric complications in women with heart disease. Matern Fetal Neonatal Med. 2016;29(14):2306-11.

13. Drenthen W, Pieper PG, Roos-Hesselink JW, van Lottum WA, Voors AA, Mulder BJ; ZAHARA Investigators. Outcome of pregnancy in women with congenital heart disease: a literature review. J Am Coll Card. 2007;49(24):2302-11.

14. Lu CW, Shih JC, Chen SY, Chiu HH, Wang JK, Chen CA. Comparison of 3 risk estimation methods for predicting cardiac outcomes in pregnant women with congenital heart disease. Circ J. 2015;79(7):1609-17.

15. Cauldwell M, Ghonim S, Uebing A, Swan L, Steer PJ, Gatzoulis M. Preconception counseling, predicting risk and outcomes in women with mWHO 3 and 4 heart disease. Int J Cardiol. 2017;234:76-80.

16. Lu CW, Wu MH, Wang JK, Lin MT, Chen CA, Chiu SN. Preconception counseling for women with congenital heart disease. Acta Cardiol Sin. 2015;31(6):500-6.

Cite this article as: Chauhan AR, Saxena N. Risk assessment and prediction of complications in pregnant women with heart disease. Int J Reprod Contracept Obstet Gynecol 2017;6:4334-8. 